\title{
Entrevista con Bernard Vincent
}

Nacido en París (1941), Bernard Vincent es un historiador de renombre en Europa y América del Sur. Consiguió su agregación universitaria en 1966, y desde sus inicios se centró en la Historia Moderna, particularmente en grupos marginales de la España de los siglos XVI-XVII.

Ha residido en nuestro país muchos años. Vincent fue miembro de la sección científica de la Casa de Velázquez inicialmente (1968-1971), algo más tarde director de estudios (1977-1978), y a continuación secretario general (1978-1982) de dicha institución. Asimismo ha encabezado el programa de cooperación francoespañol en ciencias sociales (1993-1996). Por otra parte, ha enseñado en la Universidad de París VII, en varias etapas de su vida; pero, sobre todo, ha pertenecido siempre a centros superiores de investigación: Centre National de la Recherche Scientifique (1976-1978), y a la École des Hautes Études en Sciences Sociales, en donde ha sido director de estudios desde 1988 -era doctor de Estado ya en 1986-, y luego responsable de la Sección de Historia, desde 1996 hasta hoy. Sus colaboraciones con las universidades y centros investigadores españoles han sido constantes hasta el presente. Por añadidura, ha sido miembro del Consejo Nacional de las Universidades en Francia, en lo relativo a la historia moderna y contemporánea (1987-1988, 1992-1995), y es desde hace años miembro de la madrileña Academia de la Historia.

Vincent es autor de la recopilación Les marginaux et les exclus dans l'histoire, 1979, y ha trabajado en otras muchas obras colectivas. Una parte importante de sus publicaciones las ha hecho en nuestro país: escribió en 1978 una famosa Historia de los moriscos. Vida y tragedia de una minoría, con Antonio Domínguez Ortiz, con quien mantuvo siempre un trato familiar (casi como un hijo, ha dicho una vez); en Granada se han recogido dos series extraordinarias de textos suyos, Andalucía en la Edad Moderna: economía y sociedad (1985), y Minorías y marginados en la España del siglo XVI (1987). Además, 1492. 'El año admirable' (1991), alcanzó resonancia internacional; y asimismo la ha conseguido su España. Los siglos de oro (1999), libro que conjunta imágenes y análisis temáticos de nuestra historia, hecho con Bartolomé Bennassar. Recientemente ha participado con un capítulo fundamental en la España en tiempos del Quijote (2004).

Nos gustaría que hablaras de tus inicios y de tu formación primera.

Nací en París; pero soy un parisino cuya familia proviene del suroeste de Francia, al norte de Toulouse. Allí pasaba, en Cahors, muchas vacaciones durante mi infancia y adolescencia, en casa de mi abuela y tatarabuela. Mi propia abuela materna estaba rodeada de españoles emigrados tras la guerra civil, como sucedía en toda esa zona. Ese fue mi primer contacto con España.

Hice los estudios superiores en la Sorbona, aunque mi maestro fue Pierre Vilar: era director de estudios en la sexta sección de la Escuela Práctica de 
Altos Estudios, como se llamaba por entonces. Asistía a sus seminarios, y allí se produjo nuestro primer contacto, que luego supondría mi encaminamiento investigador.

¿Cabría decir que tu Andalucía en la Edad moderna y otros trabajos paralelos evocan, eso sí, por partes, la Cataluña en la época moderna de Vilar?

No pensaba en trabajar sobre Andalucía en ese momento. En mi juventud era militante político y sindical; estábamos en la fase final de la guerra de Argelia, por ello me atraía más la historia contemporánea, y concretamente quería estudiar el anarquismo español. Al finalizar la carrera, y como no había especialistas al respecto entre los profesores de Historia española, hablé con un historiador de Alemania que estudiaba movimientos sociales en general. Acordamos que hiciese una tesina sobre Pi y Margall; fui a Barcelona -era el curso 1964-1965- y concluí al fin ese trabajo, pero no salí muy entusiasmado de la experiencia con ese político concreto; seguía motivándome más todo lo relativo a la esfera social.

Por entonces había conocido ya a Pierre Vilar, que siguió mi trabajo inicial. Insistía yo en mi proyecto sobre el anarquismo, si bien Vilar me convenció para que cambiara de época. Principalmente porque en aquellos años era muy difícil investigar ese tema: la biblioteca Arús, tan importante, estaba cerrada y sus documentos no eran accesibles; además un alumno de Vilar era hijo de un anarquista, y éste tenía acceso directo a papeles privados. Así que, ante sus preguntas, me incliné por el siglo XVI, que me gustaba, y como en la época estaban de moda los estudios regionales me dijo: «¿Y qué región?».

Contesté casi al azar: «Andalucía». Lo dije simplemente porque nunca había estado allí. Sólo conocía algo de Cataluña. Crucé por vez primera una frontera -la frontera española- cuando tenía veinte años. Provenía de una familia modesta; y mis horizontes eran bastante limitados. Yo soñaba con Andalucía al ver grabados o al leer a los románticos franceses, a Gautier y otros. Me fascinaba ese mundo. Así comenzó mi interés por lo andaluz en 1966.

\section{¿Y cómo abordaste tu tesis de Estado luego?}

Es muy posterior, y algo peculiar. Se titulaba Entre el Islam y la Cristiandad: el Reino de Granada en el siglo XVI. No respondía a una tesis clásica, pues opté por la otra posibilidad francesa: reunir trabajos publicados y hacer una síntesis de unas cien páginas. Resumía en ella algo del libro sobre los moriscos que publiqué con Domínguez Ortiz -a quien conocí en 1968, gracias a Vilar-, parte de los dos libros de recopilación de artículos que publiqué con la Diputación de Granada, también del libro que publiqué con Cortés Peña, titulado Historia de Granada, así como mi aportación al volumen IV de la Historia sobre Andalucía publicado por Planeta en 1980, y una serie de escritos más. 
En tus artículos -y no sólo en uno famoso sobre el Albaicín-, hay siempre una visión casi 'panorámica', atmosférica y humana: ¿es eco de la historia total vilariana, de las visiones de Braudel o de un «lanzarse a la vida» como decía Lucien Febvre?

No conocí a Lucien Fevbre, pero lo he admirado y leído. Mi formación debe mucho a la escuela de Annales, y entre todos, Marc Bloch es mi preferido. Es quien me ha marcado como historiador y también como ciudadano. La extraña derrota, su libro sobre la capitulación francesa de 1940 lo he releído a menudo. También he estudiado intensamente a Braudel. No sé cuántas veces habré revisado El Mediterráneo. Aún hoy lo utilizo mucho, por partes, por filones. Pero la influencia más profunda ha sido la de Vilar, junto con la de Domínguez Ortiz. He seguido su enseñanza durante años. Su visión de una historia total me parece muy adecuada y he intentado aplicarla a mi manera, al lado de los historiadores españoles. Mis preferencias metodológicas para este oficio residen en intentar centrarse sobre un terreno que se conozca profundamente. Hay quien prefiere hacer estudios más panorámicos; no es mi camino: yo intento entender un territorio concreto.

Pero esa otra 'panorámica' tendría que ver con la geografía-historia más ceñida, como se ve en tu artículo sobre los terremotos de los siglos XV-XIX, de Andalucía en la Edad Moderna, donde se funden lo geofísico, lo arquitectónico, lo arqueológico y lo histórico...

Desde luego. Y los lazos entre geografía e historia son muy importantes. No hay que olvidar que Vilar fue un geógrafo convertido en historiador; lo resalta en el prólogo de su gran obra. Pero estos lazos hoy no cuentan tanto como contaron en los años veinte o treinta del siglo XX. Luego, los historiadores se han aproximado más a los sociólogos, a los antropólogos y también sin duda a los economistas. Sin embargo, hay que dejar claro que la relación entre geografía e historia es utilísima. El historiador que no conozca bien el territorio físico carece de algo esencial.

Los estudios sobre los terremotos me parecen un buen ejemplo de la historia total. Había trabajos de geólogos y geofísicos que intentaron verlos en perspectiva histórica, pero ningún historiador los había abordado antes, que yo sepa. En 1969, estaba investigando en Almería, y en una sola tarde de archivo -me acuerdo bien- encontré cuatro o cinco referencias a los terremotos, fenómenos que hacen desaparecer poblaciones de golpe y que afectan a las mentes de quienes sobreviven: la sorpresa y el espanto van más allá de lo que ocurre ante una epidemia o una inundación. Luego encontré muchas cosas más. Creo que constituye un buen ejemplo de historia global, representa la relación del hombre con el medio físico, que es una dimensión elemental de nuestra vida: pérdidas humanas, frac- 
turas económicas, reconstrucciones, desplazamientos, reasentamientos. Hoy la historia del medio ambiente, y de sus cataclismos, está muy consolidada pero entonces apenas era tenida en cuenta... Siempre he estado atento a esas parcelas posibles de la historia poco frecuentadas.

Un terremoto produce una quiebra en las vidas, las expulsiones de minorías representan otro tipo de quiebra social. Tú has estudiado muchos márgenes de la sociedad, y cabría decir que has puesto de manifiesto lo que podría llamarse «la centralidad de los márgenes»...

Sí, me parece esencial revisar cualquier margen para establecer mejor las relaciones históricas. Los márgenes nos desvelan muchas cosas fundamentales sobre el centro, como se ve desde que se planteó, en los años setenta, el lugar concreto de la exclusión social, en sus diversas formas. En 1973 propuse, por ello, una asignatura sobre la historia de los marginados, en la Universidad de París VII. Creo que en Francia fue la primera, aunque constituía un interés común a los profesores del Departamento, pues Michelle Perrot, amiga mía, propuso al mismo tiempo el estudio de la historia de las mujeres, los «trabajos de género». Fueron propuestas paralelas, y la atención a los segregados revela bien el funcionamiento de la sociedad en su conjunto. Naturalmente, la lectura de Foucault fue una guía ante las preguntas que entonces me planteaba.

Escribiste sobre las epidemias en Andalucía o sobre la peste atlántica a finales del siglo XVI. ¿Has trabajado sobre hospitales?

La geografía de la peste implica ver el impacto económico que ésta produce, su mayor efecto en pueblos pobres que en localidades favorecidas, en las personas humildes que en las ricas, en suma, supone analizar sus vicisitudes dispares. No he trabajado sobre hospitales, aunque entre mis papeles tengo todavía muchas notas del archivo de San Juan de Dios de Granada y espero llegar a utilizarlas. Es una Orden que me atrae porque regentaba hospitales abiertos a todos los que llegaban: pobres, transeúntes de todo tipo, gente llena de incertidumbre. He encontrado libros de entradas de enfermos de algunos hospitales con datos muy valiosos.

La Orden tenía hospitales muy grandes en comparación con los demás de la época, que eran de diez o veinte camas, a lo sumo cincuenta, pero el de San Juan de Dios tenía trescientas. En los libros figuran enfermos de todo el mundo -pasan, por Granada, italianos, portugueses, franceses-; y es muy significativo que se recoja por escrito lo que llevan consigo al ingresar, lo poco que llevan; así se lee: «hato, mucha miseria», «mala ventura». Por las anotaciones se pueden deducir datos sobre las relaciones entre unos y otros. 
Esa Orden tiene hoy un hospital con mil camas en Palencia...

Sí, aún persiste la gran dimensión de los hospitales de la Orden.

Los náufragos de Declerck, sobre la indigencia hoy en día, acaba de traducirse. ¿Que opinas de él, de sus fuentes a veces aparentemente tan imprecisas?

No conozco a Declerck personalmente. Su libro me interesa por su contenido y porque se sitúa entre varias disciplinas, sociología, psiquiatría, etc. Es muy importante para las ciencias sociales esa perspectiva tan variada... Por lo demás, no hay fuentes envenenadas en la historia, o todas lo son, o pueden serlo.

La hipótesis de Foucault sobre la construcción de una sociedad disciplinar entre los siglos XVII a XVIII -talleres, armada, prisiones- ¿te parece correcta para comprender la modernidad?

Me llamó la atención El nacimiento de la clínica; pero un libro tan importante como Vigilar y castigar es el que más me ha atraído, y marcado incluso, entre otras cosas porque estuve unos años enseñando en la cárcel. Había un acuerdo entre el Ministerio de Justicia y la Universidad de París VII para que acudiéramos como profesores a la prisión; y fui todos los miércoles durante tres o cuatro años, como voluntario, por supuesto. En una celda enseñaba a un grupo de seis u ocho presos. Con los peligrosos las clases eran particulares; y en ocasiones me quedaba allí dos horas encerrado con un alumno. Fue una experiencia difícil y dura, pero muy gratificante; alguno se ha convertido en investigador, en un compañero. Por eso me atrajo especialmente el libro de Foucault y su militancia en ese campo por esos años. No lo traté personalmente, y además mi trabajo estaba alentado por las instituciones mismas; en cambio, me vi con Michel de Certeau que conocía bien su modo de ver la historia.

Falta en tu enumeración su Historia de la locura, su modo de plantear la razón y la sinrazón modernas a través de Erasmo, Cervantes, Descartes, del encierro manicomial.

Su planteamiento es muy relevante y sin duda su análisis es notable, pero reconozco que mis trabajos no van por ese camino. No es mi territorio; la historia social es el centro de mi investigación, y no he estudiado, entre los excluidos, a los que se ven afectados por la enfermedad mental.

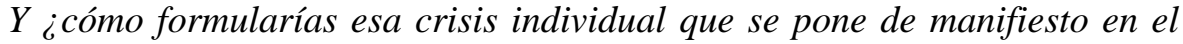
Quijote, en los libros sobre la tristeza de finales del XVI y principios del XVII, o en el género autobiográfico entonces naciente?

Lo que me interesa realmente es la relación del individuo con la sociedad. Y el Quijote en ese punto es un libro fantástico. Es una novela inigualable. Me llama 
la atención en ella la crisis de cada uno de los personajes, a través de Don Quijote o mejor de Sancho. Y también ver cómo aparecen -y se relacionan- nobles, campesinos, criados desarraigados, el morisco Ricote, las distintas caravanas de personas.

Has escrito que el análisis foucaultiano de la instauración del régimen penal -con sus tres principios, celda, taller, hospital- es magnífico; y que ciertos aparatos disciplinarios, existentes antes del siglo XVIII, fueron adoptados por la legislación decimonónica. Entre ellos, dices, la Inquisición.

Vigilar y castigar se basa exclusivamente en el noroeste europeo, también en Norteamérica, pero olvida lo que sucede en Italia, y más aún lo que ocurre en España y Portugal. Es curioso que no haga ni una mera alusión a la Inquisición o a otros aspectos peninsulares. La Inquisición supone una cárcel preventiva, desde el siglo XV. No se localiza ya en un edificio reutilizado y abierto, como antes -así, una fortaleza de la periferia, en la que incluso se entraba y salía con cierta fluidez-, sino que tiene dimensiones reducidas, está muy planificado, y se sitúa lo más céntricamente posible, dato muy relevante sobre el papel que cumple.

Su originalidad se debe a la práctica del secreto, el aislamiento y la indefensión. Sus celdas o casillas son anónimamente iguales. En suma, es una máquina bien engrasada y consciente, muy moderna en ese sentido, aunque su modelo fuese conventual... Pero la Inquisición nunca me ha parecido algo peculiar, propiamente español, sino una variante de la sociedad disciplinar que el mundo europeo conoció en su conjunto.

\section{¿El control social se hace muy visible a lo largo del siglo XVI?}

Creo que esa centuria es crucial en nuestra evolución disciplinaria. Un libro de Jacques Le Goff, La civilización del occidente medieval, fue determinante en mi formación; lo publicó a mediados de los sesenta, y en él hay reflexiones muy sutiles sobre el territorio marginal. Y es que en el Medievo ese mundo disciplinar no existía. Se percibe, sin embargo, en el paso del siglo XV al XVI, o más bien en este último.

El caso español es fructífero a este respecto, pues hay facetas que no hallamos en otras partes. El debate sobre qué hacer con la pobreza -que existe en la España del siglo XVI- es muy rico y complejo y no se encuentra en otros lugares. Lo vemos desde el temprano escrito de Vives, de 1526, hasta el de Cristóbal Pérez de Herrera, de 1592, pasando por otros escritos (Robles, Soto, Giginta). Y también en lo que representa el hospital de San Juan de Dios, muy original en ese proceso, pues es un hospital abierto a todos y a la vez está lleno de elementos modernos, como la higiene, que se exigía siempre, o con ese mostrarnos la 
relación que la sociedad establece con quien no trabaja. Ello ya está presente en Del socorro de pobres de Vives, que sugiere que todos se pongan a trabajar, o en el fallido programa de reagrupación que propone Herrera en Amparo de pobres.

\section{lenta? \\ ¿Por eso has afirmado que la sociedad del Antiguo Régimen es dura y vio-}

Es que yo creo que la sociedad es violenta, a secas. Toda sociedad lo es. Y no basta con mostrar la faz funcional, optimista, de una comunidad: una historia social equilibrada exige tener en cuenta esa violencia... El problema era cómo controlarla y disciplinarla; así, una de las pautas características del Antiguo Régimen es precisamente el esfuerzo, tan visible, para intentar disciplinar a la gente. Creo que la sociedad del siglo XVI y XVII, sí, es muy violenta; poco a poco se encontraron recursos para intentar canalizarla. Quizás la época de la Europa occidental con menos atropellos internos, vista en su conjunto, sea la decimonónica, pese a tantas agitaciones.

Hoy estamos redescubriendo otras formas de violencia que nos sorprenden muchísimo, y el reto es encontrar la posibilidad de controlarlas y aminorarlas. Me refiero a lo que sucede estos meses en la calle. En la primera mitad del siglo XX no había violencia de este tipo, al menos en la Europa occidental (en Norteamérica es otra cosa). Son nuevas formas, son explosiones no controladas. Y el estudio de lo que se puso en práctica en los siglos XVII o XVIII puede sernos útil para comprender ciertas vías. Por ejemplo, los jesuitas en la segunda mitad del XVI o en el XVII, tal y como aparece en las Constituciones de la Orden, cuentan entre sus misiones la de «hacer las paces». Así está escrito, literalmente: quieren apaciguar cada sociedad por el sermón y la confesión, también mediante su ordenamiento social. Por otra parte, el Estado moderno acapara la violencia progresivamente, y además trata de controlar la de tipo cotidiano. En cambio, ahora la situación se desborda. En las manifestaciones parisinas de estudiantes, durante esta primavera, era intranquilizadora la presencia de grupos muy violentos que asaltaban desde fuera a sus participantes. Estas situaciones -que proceden asimismo de problemas sociales-, son totalmente inéditas, dada su expresión virulenta.

¿El concepto de conflicto de clases lo integrarías ahí? ¿Qué piensas del marxismo, hay indicios de recuperación de cierto Marx?

Nunca he sido marxista ni comunista aunque, por la decisiva influencia de Vilar -el historiador francés más importante en esa línea-, he tenido, sí, muchísimos amigos de formación marxista o de militancia comunista. El concepto de lucha de clases me parece central, sin duda. Hoy no está de más un retorno a Marx. 
Nunca conviene olvidar su acercamiento a las ciencias sociales; y hay que leerlo, así como leer a ese tipo de historiadores. Por el contrario, el pensamiento de la corriente neoliberal me deja muy perplejo; y el eclecticismo actual de las ciencias sociales no me parece nada sano. Damos mucha importancia a ciertas estrategias políticas, a determinados intereses sociales, pero lo que está en juego son las grandes diferencias económicas, el desnivel entre los que tienen mucho y los que casi nada poseen. Los teóricos que abordan asuntos sociales carecen muchas veces del sentido común con que hay que acercarse a la realidad. Marx, en cambio, poseía ese sentido común: estaba en la base misma de su reflexión. Así pues, no hay que poner barrera alguna ante el pensamiento marxista. A mis alumnos les repito que es necesario conocerlo a fondo.

¿Has estado mucho en los países árabes?, ¿qué relaciones tienes con ellos? No he vivido allí. He estado en Egipto, muy poco tiempo, y en los tres países del Magreb. El que menos conozco es Marruecos. En cambio con Argelia y Túnez mantengo muchos contactos; de hecho tengo hoy alumnos de ambos países. He ido a Túnez unas dieciséis o diecisiete veces. A Argelia -que me ha obsesionado- he ido con menos frecuencia, entre otras razones por las condiciones políticas que conocemos. En 1990 se me había confiado la responsabilidad de las tesis sobre España de la Universidad de Argel. Luego, no pude volver: una buena parte de las personas de quienes me ocupaba habían emigrado.

Por cierto, en el Estado de Qatar tradujeron mi libro sobre los moriscos. No sé qué tal es la traducción. Lo hicieron sin permiso, pero no importa mucho.

Granada es un núcleo de redes sociales y de intercambios prioritario en tu obra. El salto a Málaga que haces en alguno de tus estudios, donde aparece como un puerto en verdad de peso, ¿es por el eje Granada-Málaga o por su relación con el Magreb?

Mi interés por Málaga forma parte de mi interés por el reino de Granada, que era el objeto de mi tesis. Corresponde a las actuales provincias de Málaga, Granada y Almería. No quería olvidar ninguna parcela. El puerto de Málaga es fundamental, pero el de Motril, por la pesca, también lo es. La zona de Huéscar, en el norte del reino, era importante por el comercio de la lana, como las Alpujarras lo eran por los moriscos y la economía de la seda. Me ocupé de Málaga para intentar reunir los elementos de ese puzzle.

Pero asimismo me atrae esa costa por su relación con el Magreb. Esto viene de muy atrás, de los tiempos de mi formación y de militancia política y sindical durante la guerra de Argelia. Argelia ocupa en mi formación -y en mi ser mismoun lugar muy especial. Las relaciones entre los dos países o el problema del cau- 
tiverio me seducen, así como la presencia española en el norte de África. Como veis, voy saliendo de Granada para ocuparme de la otra orilla.

El microcosmos morisco es la gran referencia de tu trabajo. Con ello has hecho visible un grupo poco conocido, has logrado mostrar que la vida española de los siglos XVI y XVII era mucho más compleja de lo que parecía, familiar y socialmente.

Desde 1950, algunos historiadores -Caro Baroja, Reglá, Lapeyre- intentaron analizar la gravedad del conflicto con los moriscos. Serían el caso paradigmático de un grupo de personas que permite cuestionar la sociedad en su conjunto. Por una parte hay que tener en cuenta que los moriscos eran bastante numerosos, tenían peso demográfico. Además, había muchas diferencias entre los que estaban en Toledo y Ávila y los que residían, por ejemplo, en Valencia. Por otra parte, unos hablaban en sus casas sólo el árabe y otros el castellano. Había muchas discrepancias: no constituían en absoluto un grupo homogéneo.

En general si la sociedad negocia es porque hay conflictos. Abogo por una historia que tenga en cuenta tanto el acuerdo como la ruptura, y me preocupa muchísimo la relación con el otro. De ese tema Foucault nos ha enseñado mucho, al ampliar el ámbito de las relaciones de poder. Por ejemplo, las que están en juego entre los esposos. Ya es difícil vivir juntos en pareja, así que la convivencia entre vecinos, unos profundamente cristianos y otros cripto-musulmanes como poco, no resultaba fácil. Lo sugestivo es ver cómo cada cual adopta una posición diferente. Entre los moriscos encontramos desde el que profesa su fe musulmana a rajatabla hasta el que se convierte totalmente y sin reservas al cristianismo; en medio se dan todas las posibilidades. Lo propio sucede en la sociedad cristiana: las actitudes son muy dispares. Eso nos hace reflexionar sobre la sociedad del siglo XVI y también sobre la actual, que presenta análogos problemas de fondo aunque sus formas sean muy distintas.

Has descrito las tres fases represivas: la conversión de mudéjares castellanos, 1500-1502; la sublevación de los moriscos granadinos, 1568-1570; y la expulsión en 1609-1614. Pero la deportación de 1570, esa dispersión por distintas zonas de la Península, ¿fue un fenómeno singular o era habitual en las monarquías europeas?

En primer lugar, constituye una manifestación relativamente nueva de la violencia de Estado en la Europa occidental. (En China habría que estudiarlo). No es nuevo en cuanto a la expulsión de ciertas personas, pues no hay que olvidar que la expulsión de los judíos se realizó en Inglaterra ya a finales del XIII y en Francia a finales del XIV. En España fue mucho más tardía, como sucedió luego en otros 
Estados europeos, hacia 1480-1500 en tierras alemanas o italianas, por ejemplo. Pero lo particular del caso español es la meticulosidad de la deportación en sí misma, la capacidad de la monarquía española para planear y aplicar el plan de desplazamiento de decenas de miles de personas. Es un modelo impresionante que se copió y se aplicó más tarde por parte de otras monarquías, como en la expulsión de los protestantes franceses en 1685, cuando se produjo la revocación del Edicto de Nantes. Supuso una verdadera técnica.

¿Esa meticulosidad se corresponde con unos reinados 'papeleros', burocratizados?

Lo que nos asombra al acercarnos a los archivos, en particular al de Simancas, es la abrumadora cantidad de papeles de los siglos XVI y XVII. Eso revela un Estado con una capacidad de gobierno y de control increíbles. Su eficacia era impresionante, y se refleja en una burocracia que se vuelca sobre los moriscos y que funciona muy bien.

Es un trabajo científico... Como lo será asimismo el exterminio nazi...

Sólo llegar a concebir ese «proyecto» en el siglo XX, antes de diseñarlo, es algo terrible ya, y su aplicación sistemática fue algo verdaderamente indecible. Pero su racismo (o nuestro racismo) no es igual al del siglo XVI; saber cómo es sirve para combatirlo mejor.

Describes los nombres y topónimos moriscos, hablas de la purificación tras el nacimiento, de la circuncisión a los ocho días o al octavo año; de los ritos nupciales; del entierro (cuerpo lavado, mirando a oriente; tumba con pan y pasas); de su alimentación (rechazo al cerdo y a lo que le rodea, rábanos, nabos y zanahorias, a los animales no desangrados); sus abluciones con agua, al levantarse y tras cada comida; de sus posiciones al orar; del viernes como día de religión, de sus prácticas sexuales. Tras las conversiones -dices- se prohíbe el sacrificio ritual, pero el baño y la conservación de las vestimentas no se considera un signo de que mantengan la fe... En fin, ¿el conflicto fue antropológico o antropológicoreligioso?

Creo que es antropológico-religioso. La cuestión religiosa está en el centro, sí; de hecho llama la atención el que las autoridades españolas den inicialmente una definición sólo religiosa del morisco. Pero muy pronto destacan otras diferencias: la alimentación, los rituales de las bodas o la lengua (aunque la lengua se relacione con lo religioso en tanto que el árabe es la lengua sagrada en la que está escrito el Corán). Y se podía procesar a alguien simplemente por haber comido cuscús... Así que también es antropológico. Se los veía como un grupo distinto a 
la sociedad mayoritaria, por la vestimenta de la mujer, o por sus prácticas religiosas del viernes. Fuentes inquisitoriales insistían, de hecho, en el foso existente entre ambos grupos.

No hay que olvidar además un aspecto que define bien el problema morisco y lo diferencia del judío: es la dimensión política. Los moriscos constituyen el elemento social que puede traicionar a la monarquía si se alía con enemigos, sobre todo con los musulmanes, aunque asimismo con los portugueses o los franceses. Hay documentos que describen supuestas complicidades con el exterior; y ese peligro se instrumentalizó en contra de ellos. Esta dimensión es global, y tampoco debe desdeñarse.

\section{Tampoco su contribución a la agricultura...}

Sí, pero ese aspecto iba más bien a su favor. Eran necesarios en muchas tareas, y los señores les protegían por razones económicas. Los aspectos económicos retrasaron la expulsión. Ya en 1570 se habla de una erradicación total; en 1582, estando Felipe II en Lisboa, una Junta estudia por su cuenta la posible expulsión y, de momento, el monarca rechazó la propuesta. Es un elemento recurrente hasta la toma de decisión definitiva en 1609.

\section{¿Pesó más la mentalidad o la economía?}

El aspecto económico es fundamental, y a favor de los moriscos. No obstante, creo que la mentalidad influyó mucho. El siglo XVI se caracteriza por la existencia de unas barreras muy fuertes entre unos y otros. Por eso aludía a otras expulsiones de judíos, en la república de Génova o en Ginebra. El camino hacia la tolerancia es lento; presenta los primeros elementos en el siglo XVII y se afirma en el XVIII. El peor momento en esa intransigencia fue, por consiguiente, el siglo XVI.

No creo en lo que escriben algunos sobre las corrientes favorables a los moriscos en el XVI. Según Márquez Villanueva no hubo complot morisco, hubo además una tendencia clara hacia la asimilación (querían integrarse) y no existió verdadero rechazo (la mayoría de los ciudadanos querría integrarlos). Su defensa es interesante y ha tenido mucho eco; es una gran aportación que no comparto. $\mathrm{Me}$ parece una visión anacrónica, y no corresponde a la realidad de aquellos momentos: era una sociedad más tensa y conflictiva de lo que parece. Es cierto que había una corriente moderada que se distingue de la radical, pero sólo se diferencia en la selección de los medios para eliminar al otro; la defensa, por ejemplo, de medios suaves, como apartarlos más lejos o evitar su concentración o favorecer matrimonios mixtos para que se diluya esa población. Pero el fin, aunque emplee otros medios, es el mismo, la desaparición del otro. "Que se acaben», decían a finales del XVI. 
Hoy se plantea el problema en otros términos, como la aceptación del otro tal y como es o como se muestra. No intentamos convertirlos u obligarlos a vestirse de un modo distinto. En fin, muchas interpretaciones son como el mal periodismo, que no dan con la forma exacta, pues la literatura tiene su importancia en la historia. No es el caso de Márquez dada su calidad inusual, que admiro, pero resulta algo ingenuo su punto de vista.

Otra represión fue la de los judíos, a quienes además se les asigna sólo actividades claramente lucrativas, de un modo exculpatorio para los cristianos.

Algunos, sí, eran mercaderes y arrendadores ricos, pero mucha gente de ellos era modesta, desde luego: sastres, zapateros, curtidores y tundidores, tejedores, especieros, buhoneros, sederos, herreros y plateros. Suele decirse que no eran agricultores, pero los había en Tudela o en Zaragoza. En líneas generales eran humildes artesanos, vendedores ambulantes, pequeños prestamistas. Estaban bastante aislados socialmente, pero con el idioma sucedía algo distinto que con los moriscos: sólo una elite hablaba o comprendía el hebreo en la segunda mitad del siglo $\mathrm{XV}$. En todo caso, las diferencias eran muchas entre ellos -eran más abundantes en Castilla, que en Andalucía-, tampoco había homogeneidad. Y la represión se mantuvo y acreció desde finales del siglo XV con los judeoconversos.

La polémica entre Domínguez Ortiz y Netanyahu, al publicar éste Los marranos españoles. Los orígenes de la inquisición, saltó a la prensa madrileña entre 1999 y 2000. Netanyahu señalaba que la mayoría de los conversos no seguían siendo judios; que éstos sólo eran una minoría muy débil e insignificante; que en general abandonaron su religión judaica y fueron acercándose al cristianismo. ¿Qué opinas?

Me siento mucho más cerca de don Antonio por varias razones. Sobre todo porque me parece muy extraño pensar que todos los judíos habían sido convertidos por completo o que estaban en camino de ser profundamente cristianos, tal y como lo piensa Netanyahu. Los hombres son capaces de resistencias activas, pero también de otras pasivas que apenas se notan. Hay muchos modos de resistir. Lo mismo les ocurría a los moriscos: los hay que piensan en integrarse enseguida; o quienes, en cambio, rechazan esa vía e intentan mantener sus costumbres de manera clandestina; o quienes se quedan a mitad de camino. Tampoco conviene olvidar el juicio del «otro», las variadísimas miradas que los demás tienen hacia estos grupos minoritarios. En principio no podemos afirmar que todos sean de determinada manera.

La visión de Netanyahu resulta ser más bien política e ideológica. Quería demostrar la existencia del racismo y del antisemitismo en todo momento, lo cual 
no siempre se comprueba en los siglos XV y XVI. Es un libro que sorprende: por una parte muestra una erudición impresionante; por otra, hay propuestas suyas poco acertadas. El antisemitismo existía, pero no llego a entender bien el problema del racismo en el XVI y XVII, y es algo que hoy me preocupa. Algunos estudiosos niegan su presencia en ese tiempo en España, pero tengo mis dudas.

Me parece interesante, en ese sentido, estudiar la visión que se podía tener de los negros porque nos puede revelar elementos para definir el racismo de la época. No tiene nada que ver con el racismo del XIX, más biológico y «mejor teorizado». Pero hay que pensar que éste no salió de la nada y que habría elementos que prepararon el terreno en un tiempo anterior. La visión del negro, del morisco o del judío habría que enjuiciarla desde esa perspectiva, si bien es todavía algo muy resbaladizo. No tengo las ideas muy claras al respecto, aunque intento ir más allá.

Es la época en la que el eje del mundo se desplaza definitivamente, el Mediterráneo se empequeñece en medio de un universo ensanchado. Has descrito con viveza el éxodo que se produce en España, con una perspectiva más general.

La civilización española en buena medida se hizo urbana, pese a lo que parezca, pues el número de habitantes de las ciudades era ya mucho más abundante, proporcionalmente, que en otros Estados europeos: había cien localidades de la Corona de Castilla que contaban con cinco mil habitantes, y suponía el 21\% del total. Sevilla alcanzó unos 120.000 habitantes en 1600. Pero es que -además de este desplazamiento interno de población-, hubo un verdadero éxodo. Con unos cien mil judíos expulsados en 1492 y otros más luego, con medio millón de musulmanes y criptomusulmanes que salen entre 1485 y 1615 -lo que representa una cantidad elevada-, con otro medio millón de individuos que parten hacia América entre los siglos XVI y XVII, suman más de un millón de personas alejadas, y buena parte de ellas padeció numerosas violencias. Todo ello sucede en una España de seis o siete millones de habitantes, lo cual supuso, en consecuencia, una verdadera convulsión.

Has trabajado sobre la esclavitud, de la que poco se sabía hace años, ejemplo extremo de movilidad forzada. Has escrito, por ejemplo, que ya en Málaga, en 1487, los vencedores cristianos esclavizaron a toda la población, a 10.000 personas, que hubo una gran cantidad de esclavos en la zona. Nos gustaría que hicieras un resumen.

Hoy sabemos bastante sobre los esclavos. Vienen estudiándose desde hace unos veinte años, y habrá un centenar y medio de títulos sobre la esclavitud en España. Este terrible problema antes se creía que había quedado zanjado en el 
siglo XVI, pero no es así: se mantuvo en Europa hasta el siglo XIX. Los principales centros de trata de negros estuvieron en España o Portugal (Cartagena, Valencia y Sevilla o, sobre todo, Lisboa y Lagos). Lo cual es un aspecto clave para comprender asimismo la trata de esclavos en América, ya que hubo tráfico humano hasta el siglo XVIII; luego pasó a América, y a partir de entonces se recrudeció la competencia entre holandeses, ingleses y franceses.

Entre los siglos XV y XIX dos millones de personas fueron esclavizadas en la Península. Se extendió mucho la esclavitud al sur de la línea que pasa por Lisboa-Madrid-Valencia. En la España moderna, destacaron en Sevilla, Málaga, Granada, donde fueron el 10 ó $12 \%$ de sus habitantes. Aunque hubiese muchos en el sur, también se encuentran en Valladolid (un 1,5\% en los siglos XVI y XVII), así como en Toledo o Madrid. Por contraste, en el norte sólo se detectan unos pocos, en el País Vasco y en Galicia. En resumen, hubo en el siglo XVI unos 100.000 esclavos, el 1\% del total de la población, con una esperanza de vida muy corta, de modo que esa minoría se renovaba de continuo.

Se está seguro hoy de la polivalencia del esclavo; podía ser doméstico o podía ser un trabajador, tanto de carga y descarga, como en la agricultura y la artesanía. Lo más destacable es que toda la sociedad podía tener esclavos: los nobles y los eclesiásticos, incluso los había en los conventos. También los tuvieron mercaderes y en ocasiones artesanos, pero menos, pues hay que tener en cuenta que su precio era elevado: 100 ducados; y como un ducado suponía cinco días de salario, exigiría 500 días de salario. Es un resumen muy rápido; además todavía queda mucho por afinar.

No parece que lo afine Les traites négrières (2004), de Pétré-Grenouilleau. ¿Podrías resumir tu polémica con él e indicarnos líneas nuevas de investigación?

Quizá viese yo el peligro de una panorámica, en el sentido global. Creo que le falta bibliografía española y portuguesa; sólo domina la inglesa, acaso por destacar los siglos XVIII y XIX. Pero en realidad hay que partir del siglo XVI o del último tercio de esa centuria; y además hay que considerar que la Península ibérica es fundamental. Y no sólo en relación con América, pues previamente la que pesaba era la trata de negros dirigida a la Europa del suroeste, en particular hacia España y sobre todo Portugal.

Por otra parte, hubo un comercio generalizado de hombres, un trato con personas capturadas y esclavizadas que buscaba lograr rescates: sucede en todo el sur mediterráneo, y no deja de tener relación con los negreros. Si los esclavos negros se usaron para las plantaciones, como él resalta, asimismo participaron en las minas y sobre todo en la vida doméstica, un aspecto capital que él tiende a soslayar. Finalmente, como otros, Pétré-Grenouilleau busca el antecedente real de la 
trata moderna en el mundo musulmán -como si todo fuese igual en el tiempo-, lo que acaba eximiendo de responsabilidad a los europeos; esto me parece grave.

Hoy me interesa, personalmente, el asunto de los santos negros. La devoción que se les tenía es impresionante, tanto en España, Portugal o las Indias. Dentro de la visión que se tenía del «otro negro», hubo un intento a finales del XVI y principios del XVII de promocionarlos, defendiendo que pertenecían al plan divino, como todos los seres humanos, y que entre los negros había también santos como sucedía entre los blancos. Descubrí que había dos de ellos en Sicilia (territorio que pertenecía a la monarquía española), que fueron objeto de mucha devoción y que eran hijos de esclavos. Unos libertos, sorprendentemente, podían llegar a santos. Resulta significativa esta equiparación, pues se observa en todo el Imperio español. En la Nueva España o en Chile encontramos huellas de semejantes devociones. Y esta sería una veta nueva para entender mejor rasgos de la esclavitud.

No hay sociedad inmóvil, has señalado últimamente. ¿Pero qué supuso la movilidad de ese período?

En una etapa de mi vida profesional leí una serie de libros, a veces escritos por amigos muy cercanos, sobre la historia inmóvil. Yo mismo he explicado en clase que hubo, sí, desde el siglo XV hasta principios del XX cambios de carácter ondulante pero que volvían al punto de partida, así en lo relativo al crecimiento por ejemplo demográfico. Correspondería todo ello a un mundo de campesinos, inmóvil, que nacían, vivían y morían en el mismo lugar, que apenas se desplazaban al hilo de sus vidas. Sin embargo, el caso español no encajaba con esa visión, lo que me llevó a muchas discusiones con algunos colegas. Durante los siglos XVI y XVII la importancia de la emigración a América fue capital, así como los desplazamientos frecuentes de los moriscos, voluntarios o involuntarios, que realizaban varias veces a lo largo de su vida. Un ejemplo más: en 1700 existía la misma población que en 1500, y si nos quedamos ahí es como si no hubiese ocurrido nada entre tanto. Pero hay que estudiar, por citar un aspecto, si los descendientes tienen más medios ya en $1700 \ldots$ La microhistoria, por cierto, permitiría reconstruir mejor la movilidad social, los infinitos lazos que crea la gente, y que distinguen cada situación histórica.

Un aspecto singular de tu libro 1492. 'El año admirable' es cómo muestras la internacionalización del conflicto con los musulmanes; que de hecho se conoció la conquista de Granada en todo el mundo por ese motivo.

Me interesaba, siguiendo precisamente con la idea de movilidad, estudiar quién componía el ejército de Isabel y Fernando cuando se hicieron dueños de Granada. Y me encontré con alemanes, suizos e italianos, con franceses e ingleses. Eso significa que España no era un país peculiar ni diferente. España era una 
nación muy europea a finales del XV, y la empresa de Granada se vio respaldada por toda la cristiandad. Hubo un movimiento común que nos explica la presencia de gentes de muchas partes. Además, hay que tener en cuenta que la movilidad era un elemento fundamental de la sociedad del Antiguo Régimen. No quiero decir que todos los campesinos se desplazaran mucho a lo largo de su vida, pero había bastantes que sí lo hacían. Estos últimos años defiendo que si la monarquía católica se mantuvo durante más de tres siglos fue precisamente por la presencia de bastante gente que tenía el sentimiento de pertenecer a un espacio plural, muy extenso. Gente que había pasado tiempo en América o en el Norte de África o en Flandes.

Has descrito esa circulación en el Quijote; ¿repercute ese hecho en nuestra literatura de la época, por ejemplo, en el Viaje de Turquía?

He abordado esa notable movilidad hace poco en «La sociedad española en la época del Quijote». Me llamaban la atención los continuos recorridos en torno a un centro que es básicamente La Mancha. Y no sólo se traslada siempre don Quijote, el andante, sino también todos los que se encuentran con él; especialmente en esta obra de Cervantes aparecen todo tipo de personas que se desplazan, todo tipo de posadas, tan significativas; hay un trasiego de bienes, ganados, presos, viajeros. Estamos ante una sociedad en tránsito incesante. Encontramos el mismo testimonio en los libros de entradas del Hospital de San Juan de Dios, por ejemplo. Es increíble la variedad de datos sobre vidas que huyen y se frustran.

El Viaje de Turquía es una ficción, pero basada en hechos reales. Hubo mucha literatura de este tipo en la época. Hay textos del final del XVI y principio del XVII que narran, por ejemplo, cómo un chaval de catorce años decide un buen día, como dice en su relato, salir «a ver mundo». Sale de su pueblo manchego, encuentra a otro joven de su edad y van a Málaga, luego a Orán con unos soldados y acaban en Constantinopla, secuestrados por unos corsarios. Es una movilidad no controlada, en la que unas veces saben lo que van a hacer y otras no.

Destacas a menudo la importancia social de la dependencia, de los dependientes de muchas familias...

Sí; suponía una gran cantidad, el 20\% de la población entre los siglos XVI y XVIII (quizá del XIX); y comprende a aprendices, criados -un mundo complejísimo-, esclavos, mucho más numerosos de lo que se pensaba, e incluso a expósitos, que permanecían a menudo ocultos. Una quinta parte de la población, pues, era dependiente, así que convenía rescatar del olvido a estos seres modestos cuya relevancia en la economía y en la sociedad misma era clara, cuyo papel era de 
hecho estructural. Pero es el mundo de los que no dejan mucha huella: ni aparecen en los libros de familia ni en los libros de defunciones.

Cuando estuve por primera vez en Madrid, en 1967 -ese Madrid enrarecido del franquismo-, me sorprendió mucho que la profesión de criado fuese la más importante. Cerca de trescientas mil personas vivían ejerciendo el servicio a los demás. Es decir, que se trataba de algo que ha existido hasta épocas muy recientes. Incluso hoy es un sector de la economía notable, aunque naturalmente tenga ahora otras facetas; su evolución es muy significativa.

Sucede que la historia de ciertas redes de relaciones o de solidaridad -cofradías, comunidades en el mundo rural, facciones en el reparto del poder local- hace olvidarse de las desuniones en una sociedad, no sólo de la estricta marginalidad sino del mundo de quienes son ajenos a las redes fundamentales. En la historia social hay que estudiar a los campesinos, los artesanos, los obreros, los burgueses y los nobles, pero también a todo ese grupo de dependientes que no ha suscitado el suficiente interés en los investigadores. Mucha historia se fija especialmente en los ricos, y no en los pobres, pero los estudios de los setenta intentaron invertir la perspectiva.

Lo que abordaron José Antonio Maravall (en La picaresca desde la historia social) y Geremek (en La piedad y la horca o en La estirpe de Caín), muestra que los criados se hicieron más conflictivos en el siglo XVI. ¿Coincide con tu perspectiva social?

Son libros muy importantes y pioneros, producto de la reflexión de los años sesenta y setenta; nos han enseñado parcelas de la historia que conviene recordar siempre. Maravall se basa en un profundo conocimiento de los textos publicados en la época, y sus trabajos han encontrado un paralelo con la obra de Geremek, basada en documentos de archivo. Y así Geremek nos muestra entre otras cosas, cómo existía una solidaridad entre esos grupos marginados o dependientes, pero le faltó investigar la complejidad real de las relaciones entre amos y sirvientes. Una vez más, las aportaciones de Foucault nos ayudarían a entender esa complejidad: muchos aspectos se nos escapan.

¿El criado se hace más independiente porque la sociedad se vuelve menos familiar, más anómica?

Sucede así, indudablemente; aunque, por otra parte, no hay que olvidar nunca la capacidad de resistencia y organización de los grupos más pequeños y modestos. Esto hace que la mirada sea más activa, que busquemos cómo llegan a defenderse ciertas capas de la sociedad, más allá de esa anomia que los haría pasivos... 
Las relaciones, por tanto, son reversibles...

Sí. Por ejemplo, la película de Losey, El criado, sería reveladora sobre un cambio de relaciones. Cada individuo tiene recursos para cambiar el sentido de su camino. Y la película muestra esas gradaciones; si ves los cinco primeros minutos y los cinco últimos crees imposible que exista continuidad en ese relato; pero lentamente se fue modificando todo...

Es el poder de los dependientes...

Sí. Parecen en principio tener pocas posibilidades de ejercer el poder, pero no se puede descartar totalmente que lo logren. Y yo añadiría: ¡ojalá sea así!

F. Colina y M. Jalón

\section{BIBLIOGRAFÍA}

Entre sus publicaciones resaltan, en primer término, Historia de los moriscos. Vida y tragedia de una minoría, Madrid, Alianza, 2003 (or. 1978; trad. árabe, Qatar, 1984), con A. Domínguez Ortiz; Andalucía en la Edad Moderna: economía y sociedad, Granada, Diputación, 1985; Minorías y marginados en la España del siglo XVI, Granada, Diputación, 1987; así como 1492, 'El año admirable', Barcelona, Crítica, 1992 (or. 1991; aumentada en 1996; trad. en Portugal y Brasil, Alemania e Italia), es una obra premiada en Francia, en 1992 y 1993. Y se ha difundido mucho España. Los siglos de oro, Barcelona, Crítica, 2000 (or. Le temps de l'Espagne XVI ${ }^{e} X V I I^{e}$ siècles, 1999; que fue traducida al alemán), con Bartolomé Bennassar. Destaca recientemente «La sociedad española en la época del Quijote», en A. Feros y J.E. Gelabert, eds., España en tiempos del Quijote, Madrid, Taurus, 2004.

Pero asimismo deben recordarse sobre el mundo granadino: «Andalucía oriental moderna», en Los Andaluces, Madrid, Istmo, 1980, pp. 107-134; «Economía y sociedad en el Reino de Granada en el siglo XVI», en Historia de Andalucía, t. IV, Barcelona, Planeta, 1980, pp. 160-223; «Economía y sociedad en el Reino de Granada en los siglos XVII y XVIII», en Historia de Andalucía, t. VI, Barcelona, Planeta, 1981, pp. 352-401; Historia de Granada, III, La época moderna, siglos XVI, XVII y XVIII, Granada, Don Quijote, 1986 (con A.L. Cortés Peña); Terres de Grenade, París, Arhis, 1987 (con A. Bazzana y A. Humbert) y la pequeña monografía Grenade, un guide intime, París, Autrement, 1989. Podemos añadir: «La disidencia morisca», en VV. AA., Disidentes, heterodoxos y marginados, Salamanca, Universidad, 1998; «El río morisco», en VV. AA., La expulsión de los moriscos, Madrid, Comunidad, 1998; o «Granada tras la reconquista», en VV. AA., Los Reyes Católicos y Granada, Madrid, Soc. Est. Conm. Cult., 2004; «Sur une relecture de l'histoire de la traite négrière: débat», Revue d'Histoire Moderne et Contemporaine, 52-4 bis, 2005.

Añadimos otros trabajos de documentación: 1492, les royaumes ibériques, París, Cahier de la documentation française, 1992 (con J.-F. Schaub); Dictionnaire des biographies. IV, Le Monde moderne (vers 1480-1815), París, Armand Colin, 1995 (con J. Béranger y J.-M. Bizière), ciento veinte biografías españolas, portuguesas e italianas; y el prefacio a la reedición de Antonio Gallego Burin, Alfonso Gámir Sandoval, Los Moriscos del Reino de Granada según el sínodo de Guadix de 
1554, Granada, 1996, pp. IX-LII. Además de publicar 150 artículos, B. Vincent ha realizado las siguientes ediciones: un libro extenso Les marginaux et les exclus dans l'histoire, París, 1979; État et Eglise dans la genèse de l'État moderne, Madrid, 1986 (con J.-Ph. Genet); el número monográfico sobre «Espagne, Espagnes, $\mathrm{XV}^{\mathrm{e}}-\mathrm{XX}^{\mathrm{e}}$ siècles», Revue d'Histoire Moderne et Contemporaine, 412, abril-junio 1994; Granada 1492-1992, Del reino de Granada al futuro del Mundo Mediterráneo, Granada, 1995 (con M. Barrios Aguilera); Les figures de l'administrateur. Institutions, réseaux, pouvoirs en Espagne, en France et au Portugal, XVI ${ }^{\mathrm{e}}-\mathrm{XIX}^{\mathrm{e}} 16 e-19 e$ siècle, París, 1997 (con R. Descimon y J.-F. Schaub); L'Espagne, l'État, les Lumières, Madrid-Burdeos, Casa de Velázquez, 2004 (con J.P. Dedieu).

* Entrevista realizada el 8-VI-2006. 